\title{
Young men, sexual health and responsibility for contraception: a qualitative pillot study
}

\author{
Sally Brown
}

Research Fellow, Wolfson Research Institute, Durham University, Stockton on Tees, UK

\section{Correspondence to}

Dr Sally Brown, Evaluation, Research and Development Unit, Wolfson Research Institute, Durham University, University Boulevard, Stockton on Tees TS17 6BH, UK;

s.r.brown@durham.ac.uk

Received 11 April 2011 Accepted 5 September 2011 Published Online First

1 November 2011

\begin{abstract}
Background and methodology Despite increasing interest over the last decade or more in men's views of sexual health services and use of contraception, most published literature focuses on women. It is important that the views of boys and young men are better understood, particularly with regard to responsibility for use of contraception. This pilot study aimed to gain insights into young men's views of sexual health services and contraception; five non-fathers aged between 14 and 18 years took part in two focus groups. The groups were recorded, transcribed and analysed using the constant comparative method to build up categories of data.

Results Engaging young men in research is very difficult, particularly young men who are not in education or employment. Young fathers proved impossible to recruit. The young men who took part in the study thought responsibility for contraception was shared, although this was partly dependent on relationship status, namely whether sex was with a regular partner or a one-night stand.

Discussion and conclusions These findings are based on a small sample and all participants were in full-time education. It is likely that attitudes may differ from those who are not in education, training or employment. In a future study, it would be important to ensure that young men from different class and educational backgrounds are included in the research, as the tentative conclusions from this pilot study suggest that educational status is a factor in beliefs about responsibility.
\end{abstract}

\section{Background}

Despite increasing interest over the last decade or more in men's views of sexual health services and use of contraception, most published literature focuses on women. This is even more so with young people, where a focus on teenage pregnancy has resulted in young men being, if not invisible in the research, certainly harder to find. ${ }^{1-3}$ Although, as a result of this policy focus in the UK, resources

\section{Key message points}

- Engaging young men in research on sexual health issues is a major challenge, and lack of engagement among certain groups (e.g. those no longer in education, young fathers) may mean they are absent from the literature on this topic.

- Young men's views on responsibility for contraception are influenced by relationship status.

- Young women must choose between protecting their health and physical wellbeing by carrying a condom, or protecting their reputation by not being seen to be a 'slag'.

have gone into research aimed at exploring the needs and behaviour of young men, much of the resulting literature, and associated research ${ }^{45}$ has been guidance from the Department of Health and Teenage Pregnancy Unit, which informs practice but does not appear in academic literature.

Access to sexual health services designed for young people, taking into account their particular needs and fears, is important. ${ }^{6}$ Boys have some of the same concerns as girls, such as visibility and the need for confidentiality, ${ }^{78}$ but boys' sense of responsibility for contraception is not as well developed. ${ }^{9}$ For both sexes negotiating condom use can be difficult. ${ }^{10} 11$ Boys and girls wish for more, and better, information about sex; ${ }^{12}$ boys are also much less likely to obtain information from their families. ${ }^{13}$ It is important that the views of boys and young men are better understood, particularly with regard to responsibility for use of contraception.

\section{Methodology}

This study aimed to gain insights into young men's views of sexual health services and contraception. It was conducted first as a pilot of the methodology, to explore whether this would be a successful means of engaging with young men of diverse backgrounds in terms of education, social class and experience of fatherhood. 
Second, it aimed to identify themes that may be important to this group, to be explored in a larger study. Focus groups were chosen as they are a useful method for exploring different perspectives within a social network and exploring group norms. ${ }^{14}$ It was felt that this methodology was appropriate for this study, as it would allow the investigation of how group norms and expectations inform young men's views about responsibility for contraception. However, the potential disadvantage is that participants may occupy a position that is seen as acceptable within the group, which may obscure individual views. In addition, the facilitator was older and female, which again may have influenced the participants, in that to a large degree they conformed to a desirable positioning of themselves as being responsible.

The original intention was to hold four focus groups: two with young fathers and two with non-fathers. Despite repeated efforts, aided by the boys and young mens' sexual health co-ordinator, it was not possible to recruit young fathers. Several reports have noted the lack of engagement of fathers, particularly young fathers, with sexual health services ${ }^{15}$ and the difficulties of engaging them in research. ${ }^{16}{ }^{17}$ It was hoped that accessing young fathers via an established service (Young Dads Drop-in) would increase the likelihood of their participation. Unfortunately the Drop-in was not held during the initial course of recruitment for this study, and when it began again, attendance was very low. Despite meeting a number of young fathers at the Drop-in and discussing the project with them informally, they either declined to take part or, when they did agree, did not keep appointments.

Two focus groups with non-fathers were held, and the results are presented here. The participants were recruited by youth workers asking for volunteers among young men who attended youth groups. The study was explained to the participants by the youth workers, and they were asked to consent to take part and for the focus groups to be recorded. Each group lasted for approximately 40 minutes, were run by the author, and were recorded and later transcribed. The topic guide included sources of knowledge about sexual health (sex education at school, other sources of information), access to sexual health services and obtaining contraception and responsibility for contraception. Transcripts were analysed using the constant comparative method to build up categories of data. ${ }^{18}$

Those non-fathers who did participate were keen to talk about their views and experiences. Pseudonyms are used to ensure the confidentiality of the participants. The first focus group (FG1) involved Joe aged 15 and Mike aged 16, both at school. They were friends, and the discussion was peppered with a great deal of teasing and joking. This group might more properly be described as a paired interview between friends, as their friendship did appear to have an impact on the way they spoke; they revealed information about each other that might not have been revealed in a more traditional focus group, for example, that one was a virgin and one had been in a steady relationship for almost 3 years. The second group (FG2) involved Tom aged 14 (at school), Sam aged 17 (at college) and Rob aged 18 (at school). In this group, it was up to the individuals to reveal information about themselves, which they chose to do in terms of sexual experience, but unlike FG1, they did not know each other well enough to reveal each other's experiences.

Attempts were made by the Young Men's Health Worker to recruit participants from groups of young men not employed or engaged in education, but as with the young fathers, they were not willing to participate. This highlights the difficulties mentioned above of engaging in research with young men who are themselves disengaged from education and employment.

\section{Results}

Participants thought that sex education should be introduced at a younger age and made part of the normal curriculum instead of being singled out and presented as something that was "frowned upon". In this way it was felt that it may become easier for young people to talk about sex and contraception.

If they had problems that they wanted to talk about, the young men reported that they would consult their general practitioner. None of them mentioned talking to their fathers, and where mothers were mentioned there was a suggestion by Joe, however jokily made, that they might not be reliable sources of information as she had had him when she was 18 years old. In both groups, there was a sense of waiting until the 'right' time as far as having a family was concerned, and it was felt that this was influenced by family background, particularly where having a very young mother might normalise early childbearing.

Participants acknowledged that sexual reputations and expectations play a part in determining behaviour, ${ }^{19}$ but their views about responsibility and the use of contraception were largely delineated along gender lines, arguing that girls and boys think differently about contraception:

Mike: Most boys are prepared not to use [condoms], but girls generally are like, "no you must use them".

Joe: Yes, girls are very keen to use them.

At the same time as saying that girls are more insistent on using condoms, they see the responsibility as lying with boys:

Interviewer: Whose responsibility is it, do you think, if you're in a relationship, to sort out contraception?

Joe: Boys, I think.

Mike: Yeah.

Joe: 'cause they've got to protect their thing.

Mike: 'cause they're doing it, aren't they?

It's their fault if anyone gets pregnant. 
Although Sam and Rob acknowledged that girls and boys might have different attitudes to wanting to use contraception, they thought that responsibility is shared:

Sam: In my experience, no. I think it's shared really.

Rob: It's shared. You're both going to do it.

The groups discussed whether or not people should carry condoms with them as a way of 'being prepared', and this raised some conflicts:

Mike: I think it's always safe for a girl to carry them. Joe: Everyone should have them, boy or girl.

The younger boys having both said that everyone should carry condoms, then had very clear ideas about what kind of girl would carry condoms to a party:

Joe: To be honest, I'd think she was a slag ...

it's like she knows she's going to have sex.

Interviewer: But what if she wasn't planning

to have sex, but thought she might want to?

Joe: Yeah but why would she carry one?

Just for a laugh? I mean, if she goes to a

party carrying a condom she knows she's

going to have sex. Definitely knows.

Mike: I don't know. I think if you go to a party

and you know there's going to be drinking, you

might not initiate sex but if you think you might get

drunk and you don't know what you're going to do, then I think it's probably best to bring a condom.

Mike appears to be more willing to allow for the influence of alcohol, and its loosening effect on people's inhibitions. This discussion highlights the dilemma faced by girls when deciding whether to carry condoms; not carrying condoms increases the risk of unprotected sex, but carrying them increases the risk of a damaged reputation. ${ }^{10}$

Rob and Sam did not label girls this way, and felt that responsibility in that setting would still be shared. The differences between FG1 and FG2 may be as a result of the age difference of the participants. Although Sam and Rob discussed how boys would refer to girls as slags, they at no point said that they themselves viewed girls who carried condoms or had one-night stands as such. Asked whether they thought people went out to clubs and parties intending to have one-night stands, they both agreed that this was the case. Asked to think about whether a girl would ask a boy to wear a condom, and if she did, his likely reaction, they responded:

Sam: They probably would [ask].

Rob: I don't think they'd say it, but if they

did, I think the boy would say OK.

The key difference as far as using condoms was concerned was how well one knew the partner:

Sam: You probably should still use one...

Rob: ... if it's someone you don't know properly.

Sam: Yeah. Unless you're in a relationship.

It appears that a crucial differential in terms of both expected and acceptable behaviour was whether or not people are in a relationship, or having one-night stands.

\section{Discussion}

This study found that these young men regard contraception as largely a shared responsibility, or their own responsibility to protect themselves, although this viewpoint is mediated by differences in relationship status. The findings highlight the difficulties young women have in making choices about protecting themselves, essentially between protecting their health and physical wellbeing by carrying a condom, or protecting their reputation by not being seen to be a 'slag'. These findings are based on a small sample, took place in the north of England, and all participants were white and in full-time education. It is likely that attitudes may differ from those who are not in education, training or employment. Nevertheless, although the findings are not generalisable, they highlight areas for further study and considerations for choice of methodologies, particularly recruitment strategies.

In a future study, it would be important to put in place recruitment strategies that were sufficiently wide ranging and inclusive to ensure that young men from different class and educational backgrounds are included in the research, as the tentative conclusions from this pilot study suggest that educational status plays a role in beliefs about responsibility. It would also be important to consider the sexual experience of those taking part in focus groups, both in the way that it might influence discussions, and how young men's views might change depending on their experience. Exploration of issues around gender and masculinities, ${ }^{20}$ encompassing discussions about views of the life course, would enable deeper understanding of the roles that responsibility and family play for contemporary boys and young men.

Acknowledgements The author would like to thank Ms Gail Teasdale, Ms Mel Clarke, Mr Simon King and Mr Neil Wade for their help with this study, and all the young men who participated in the focus groups.

Funding The study was funded by Hull City Council Teenage Sexual Health Services.

Competing interests None.

Ethical approval The study was given ethical approval by the School of Medicine and Health Research Ethics Committee, Durham University, Durham, UK

Provenance and peer review Not

commissioned; externally peer reviewed.

\section{References}

1 Lohan M, Cruise S, O'Halloran P, et al. Adolescent men's attitudes in relation to pregnancy and pregnancy outcomes: a systematic review of the literature from 1980-2009. J Adolesc Health 2010;47:327-345.

2 Pearson S. Men's use of sexual health services. J Fam Plann Reprod Health Care 2003;29:190-194.

3 Pearson S. Promoting sexual health services to young men: findings from focus group discussions. J Fam Plann Reprod Health Care 2003;29:194-198. 
4 Gelder U. Boys and Young Men: 'Half the Solution' to the Issue of Teenage Pregnancy - A Literature Review. Newcastle upon Tyne, UK: Department of Health, Directorate of Health and Social Care, Public Health Group North East and University of Newcastle, School of Geography, Politics and Sociology, 2002.

5 Lloyd T, Forrest S, Davidson N. Boys and Young Men's Health: Literature and Practice Review: An Interim Report. London, UK: Health Development Agency, 2001.

6 Craig G, Stanley N. Visibility, immobility and stigma: young people's use of sexual health services in rural areas. Child Soc 2006;20:171-182.

7 Stanley N. Thrills and spills: young people's sexual behaviour and attitudes in seaside and rural areas. Health Risk Soc 2005;7:337-348

8 Stone N, Ingham R. When and why do young people in the United Kingdom first use sexual health services? Perspect Sex Reprod Health 2003;35:114-120.

9 Hooke A, Capewell S, Whyte M. Gender differences in Ayrshire teenagers' attitudes to sexual relationships, responsibility and unintended pregnancies. J Adolesc 2000;23:477-486.

10 Hillier L, Harrison L, Warr D. "When you carry condoms all the boys think you want it": negotiating competing discourses about safe sex. J Adolesc 1998;21:15-29.

11 Flood M. Lust trust and latex: why heterosexual men do not use condoms. Cult Health Sex 2003;5:353-369.
12 Forrest S, Strange V, Oakley A; the Ripple Study Team. What do young people want from sex education? The results of a needs assessment from a peer-led sex education programme. Cult Health Sex 2004;6:337-354.

13 Measor L. Young people's views of sex education: gender, information and knowledge. Sex Ed 2004;4:153-166.

14 Barbour RS, Kitzinger J. Developing Focus Group Research: Politics, Theory and Practice. Thousand Oaks, CA: Sage, 1999.

15 Lloyd N, O'Brien M, Lewis C. Fathers in Sure Start Local Programmes (DfES Report NESS/SF/004). Nottingham, UK: DfES Publications, 2003.

16 Swann C, Bowe K, McCormic G, Kosmin M. Teenage Pregnancy and Parenthood: A Review of Reviews: Evidence Briefing. 2003. http://www.nice.org.uk/nicemedia/documents/teenpreg_ evidence_briefing.pdf [accessed 16 September 2010].

17 Reeves J. "Tell me your story": applied ethics in narrative research with young fathers. Children's Geographies 2007;5:253-265.

18 Green J. Commentary: grounded theory and the constant comparative method. BMJ 1998;316:1064-1065.

19 Marston C, King E. Factors that shape young people's sexual behaviour: a systematic review. Lancet 2006;368:1581-1586.

20 Frosh S, Phoenix A, Pattman R. Young Masculinities: Understanding Boys in Contemporary Society. London, UK: Palgrave, 2002. 